\title{
Reverse translation of child abuse to an animal model
}

\author{
Brent A Vogt ${ }^{1,2 *}$ \\ ${ }^{1}$ Cingulum Neurosciences Institute, USA \\ ${ }^{2}$ Department of Anatomy and Neurobiology, Boston University School of Medicine, USA
}

\section{Introduction}

Child abuse is a serious problem in American society. With every passing month there are new revelations including that by priests, college coaches, politicians, and sex traffickers. These experiences often leave permanent scars on the brains of the survivors of such abuse that last long into adulthood, are poorly treated and cannot be simply overlooked. Due to the shame associated with it, survivors are less likely to seek what little help there is. Indeed, effective treatment can only emerge from detailed brain studies of what occurs during and after abusive events. One such approach is the use of animal models but this has been impeded by a general misunderstanding by the experimental scientific community of what can and cannot be accomplished with such models. Clarifying these misconceptions is the purpose of the present commentary.

It is important to draw a red line where socially inappropriate behaviors such as groping, sexual harassment and other unwanted advances end and where harsh physical abuse, which we are trying to model, begins. Two reviewers of this work asked, "Were social stimuli considered, i.e., social trauma?" and "Can you really appeal to 'socioeconomic factors' in discussing your results." An animal model cannot address these issues and they are not raised as relevant. Nociceptive (pain)-evoked stress during predatory or disciplinary assault is at issue; not socioeconomics. Severe physical abuse in humans is defined by being hit with an object, burning, or forced penetrative sex at least once a month for at least a year [1]. The New York City Alliance against Sexual Assault (web site) states, "adolescents are more likely to experience sexually violent crimes than any other age ... Rape of males is any sexual assault involving forced penetration of the anus or mouth by a penis or other object." Sexual abuse is forced sex and only lifethreatening force predicts adult health status [2,3], while abuser gender does not predict symptomatology [4]. Thus, this model we developed emphasizes the early stages of the physical parameters of abuse rather than socioeconomic factors. As discussed below, animal models do not seek a complete replication of the human experience and this may be a virtue.

\section{Epidemiology}

The importance of this problem is emphasized by numerous epidemiological studies on psychiatric outcomes associated with harsh physical child abuse and rape in children including depression, hopelessness, dependency, suicide, violence, impulsivity, drug abuse, and borderline tendencies [5]. Conversely, various childhood adverse events are reported by patients with Borderline Personality Disorder (BPD) and the most frequent is sexual abuse with $40-71 \%$ of inpatients reporting it and the severity of borderline psychopathology has been linked to the severity of childhood sexual abuse [6]. Patients with BPD who currently injure themselves (known as cutting) show lower pain sensitivity than those who have stopped self-injury [7]. Patients with BPD have higher pain thresholds than controls in response to identical heat stimuli and patients report engaging in self-injurious behavior due to its immediate relief effects on emotional tension and the perception of relaxation.

It appears that many adult-onset psychopathologies and somatic diseases may to some extent also be attributed to child abuse. These include arthritis [8], fibromyalgia [9], pelvic muscle problems [10], headache [11], migraine [12], temporomandibular disorder [13], chronic widespread pain [14], vulvodynia [15], gastrointestinal diseases [2,16] panic [17], somatic disorders [18], depression [19,20], and posttraumatic stress disorder [21,22].

\section{Human imaging}

Some structural and functional imaging studies report intriguing brain alterations associated with a history of child abuse including but not limited to the anterior cingulate and midcingulate cortices [23-25]. It is surprising, therefore, that no efforts have been made to reverse translate key issues into an experimental animal model. This translational deficiency means that molecular, cellular and detailed circuit changes evoked by abuse cannot be analyzed and, in the longterm, rational therapeutics cannot be developed proximal to the abusive events to block adult-onset psychopathology. Moreover, a neurobiology of abuse cannot evolve until such a model is available for neuroscientific research. We attribute this failure by the scientific community to a misunderstanding of what child harsh physical abuse is and how to begin the modelling process by first emphasizing the early painful/stressful events; more dynamics such as social interactions can be added to the model as observations accumulate.

\section{Animal models: General issues}

There are difficulties simulating the human condition in experimental animals, but in many instances the drawbacks in humans can become virtues in animal research. One impediment is heterogeneity; i.e., all children/adolescents have different genetic makeups, find themselves in different contexts during the abuse, the abuse can occur at different times of their life, the relationship of the abuse to evoked symptoms (fear, anxiety, stress, pain) can be quite complex and may evolve over time into different disease states some of which are termed functional pain syndromes like fibromyalgia and

Correspondence to: Brent A Vogt, Ph.D, Department of Anatomy and Neurobiology, Boston University School of Medicine, USA, Tel: 315-280-6847, E-mail: bavogt@bu.edu / bvogt@twcny.rr.com

Received: December 0, 2017; Accepted: December 23, 2017; Published: December 26, 2017 
some types of temporomandibular joint disorder. Indeed, children do not become aware of their abuse often for decades after the experiences and their reports may only become useful in late adolescence (ages 20-25 and beyond). Thus, there are so many unknowns when working with abused children, it is almost impossible to determine cause and effect in terms of their experiences and brain changes much less devise treatments. We have argued that some of these problems can be overcome with animals and in some instances completely avoided. Failure to develop an animal model may be attributed to this lack of understanding of key abuse issues by the experimental community. Commentaries on research proposals and article submissions on our first work [26] provide a sampling of such concerns as noted throughout this commentary.

This brings us to the general issue of using animal models. Of course, all mammals can be abused; however, no neuroscientist thinks that an animal experiences the same perceptions of abuse as humans. Animals are required for 4 reasons. First, the same strain can be used such that genetic differences play a minor role in variability of responses to abuse. Second, the onset, duration, and characteristics of the abuse can be standardized, while in humans these factors can only be estimated, if they are determined at all. Third, although animals cannot tell us about their internal feelings, they can be tested behaviorally and provide a window into their world of abuse. Fourth, the brains can be removed in order to explore protein changes that occur during and after the abusive events. This is a critical issue as it will lead eventually to identifying what networks (connected nodes) are involved and how to fix them soon after the abusive events.

No animal model is an exact replication of any human disorder but rather is used to study aspects of a disease. Mice overexpressing amyloid- $\beta$ peptide and showing memory deficits is a model of Alzheimer's disease that allows one to assess the synthesis and degradation of this peptide and potential relationships with neurodegeneration and altered behavior; yet no one would claim that this is an exact equivalent to the human disease. This does not negate the model and can be viewed as a strength as some confounding variables in humans may be avoided as is the case with our abuse model. For example, although adolescent harsh abuse is influenced by socioeconomic factors [9], abuse is initiated with intense physical pain and stress, usually by a male predator on a young female, and it is not known what occurs in the brain independent of socioeconomic factors. The physical parameters of the primary abuse event can be simulated experimentally with controlled frequency, duration and amplitude of noxious/stressful stimuli, assessment of single neuron responses and postmortem brains and would show the effects of harsh physical abuse without confounding human psychosocioeconomic factors.

Animals provide a standardized approach to abuse, brain changes and possible interventions in order to block adult-onset psychopathology. It does not engage socioeconomic factors. The goal of such work is to devise effective treatment strategies that have not emerged from human studies.

\section{An animal model of harsh child abuse}

The first attempt to model child abuse was published by Vogt et al. (2017) [26]. The abuse was short (21 min) bouts of forced, noxious distension of colorectal tissue (nCRD), 3X/week for 3 weeks. Some neuroscientists have incorrectly assumed this is a form of chronic visceral pain but this is not the case as addressed in the Discussion of this article. In fact, it is a nociceptive-stress model; i.e., pain-evoked stress. The behavioral task of contextual fear showed that some animals were vulnerable to the abuse and others were not (resilient). The study focused mainly on ACC for reasons discussed in the Introduction of this article where there is also a brief consideration of the little we know about the brain imaging in human abused and raped children. Finally, a large portion of this article reports neuronal responses to noxious stimulation and was not written for the layperson; however, the general reader will be engaged by the Introduction, first part of the Methods that describes the model, first part of the Results that describe behavioral results and the Discussion.

\section{Comments on the abuse model that impair scientific progress}

Reviewers of grant applications and articles for publication provide interesting insights into why a neurobiology of child abuse has not yet gone mainstream. A few quotes from our experience are enlightening as some have already been mentioned above. First, reviewers have the impression that face validity requires all features of human abuse be addressed and this is not the case. One said, "Child physical and sexual abuse can never be accurately modeled in animals. Only cautious parallels can be drawn. The Principle Investigator has laid out too many similarities between humans and the present model." This reviewer is over interpreting what has been done and claimed. It seems that one would seek as many similarities as possible to achieve face validity. Another said, "The validity of nCRD as an ecologically relevant model of adolescent human physical abuse or sexual assault is highly questionable and thus its translational relevance to mechanisms of development of psychopathology ... is also questioned" and another said, "It is hard to understand how this is "a simulation of physical parameters of child abuse." Our article on this subject summarizes the model of the physical parameters of child abuse that includes 1) an age approximating late childhood/early adolescence, 2) painful stimulation (nCRD, $60 \mathrm{mmHg}$ ) with the distender simulating the male penis during anal intercourse, 3 ) short duration stimuli of $\sim 21 \mathrm{~min}$ to simulate time to male ejaculation, 4) forced stimulation by holding the distender in place, and 5) repeated events (3X/week for 3 weeks). Thus, the protocol engages conscious pain/stress systems for only a total of $\sim$ two hours.

Another issue that is of interest to reviewers is what to call the model. One said, "it is a model of the role of ACC in anticipation, discomfort, pain and anxiety." This is a summary of the functions of ACC and not a correct designation of the model. Another said, "simply define the colorectal distention model alone which is clearly aversive." Yes, it is and must be aversive, but the nCRD is only part of the protocol to generate the early stages of human abusive events. Another said, "The paradigm seems more like a model of visceral pain and social isolation and lacks the intra-species, social dyadic components of human abuse or sexual assault." There are many reasons why the model is not one of chronic visceral pain as enumerated in the Discussion by Vogt et al. [26]. Further, the animals were not socially isolated and the model does not consider maternal neglect, although a separate study of this issue is justified. The "social dyadic components" have been addressed above. Another statement reads, "Is 'more precise coding of visceral stimuli' a result of reflex visceral motor activity, transduction, inputs of nonvisceral with visceral inputs, transmission or processing. How would you know? "We would know this by recording from peripheral and brainstem nuclei engaged in visceral processing such as the nucleus of the Solitary tract. This experiment seems to present a low probability of success as these nuclei are not engaged in the same functions as ACC/ MCC as also noted below.

Finally, "The statement that 'such a model would show the effects of harsh physical abuse without confounding human psychosocioeconomic factors' gets at the central problem. The model 
is repetitive noxious stimuli and many of the effects ... could simply be due to neuroplastic changes at any level of the neuraxis (spinal, thalamic, somatosensory etc.) without having to require any kind of a fear-related or other top-down component." The spinal cord, thalamus and somatosensory cortex are not engaged in contextual fear as tested in this model but the reviewer appears unaware of this literature. Also, there may be many other non-ACC areas in the brain that contribute to child abuse disorder, but different methods will need to be employed to identify them. More importantly, if the reviewer is claiming that fear is not a serious component of repetitive, forced child abuse, he/ she is mistaken. A case report by Terr [27] makes this very clear; "A girl was sexually misused by her father from ages $5-15$, at which time she ran away ... As a married adult of 38 , she feared sex with her husband unless she initiated the act herself. She responded to the female-ontop or side-to-side positions, positions that had not been originally taken by her father. Any sexual positioning that was evocative of the incestuous set of sexual postures stimulated fear, pain, and revulsion." They also ask, "Does this article really have direct implications for sexual function (and) emotional development...?" It appears to be so and, unfortunately, scientific claims and concerns are primarily tangential to the model and its outcomes.

\section{Conclusions}

Clearly child abuse is a serious and ongoing problem in our society and has many adult repercussions. Yet, without an animal model, we will never be able to characterize brain plasticities evoked by harsh physical child abuse, with or without aspects of social support, much less develop rational drug therapies for survivors proximal to their abuse. This commentary argues against the key impediments, broached by investigators, to scientific progress toward these goals. The hope is that these impediments can be overcome to provide hope for survivors through brain research.

\section{References}

1. Bremner JD, Randall P, Scott TM, Capelli S, Delaney R, et al. (1995) Deficits in short-term memory in adult survivors of childhood abuse. Psychiatry Res 59: 97-107. [Crossref]

2. Leserman J, Drossman DA, Li Z, Toomey TC, Nachman G, et al. (1996) Sexual and physical abuse history in gastroenterology practice: how types of abuse impact health status. Psychosom Med 58: 4-15. [Crossref]

3. Leserman J, Li Z, Drossman DA, Toomey TC, Nachman G, et al. (1997) Impact of sexual and physical abuse dimensions on health status: development of an abuse severity measure. Psychosom Med 59: 152-160. [Crossref]

4. Briere J, Elliot DM (2003) Prevalence and psychological sequelae of self-reported childhood physical and sexual abuse in a general population sample of men and women. Child Abuse Neg 27: 1205-1222. [Crossref]

5. Grilo CM, Sanislow C, Fehon DC, Martino S, McGlashan TH (1999) Psychological and behavioral functioning in adolescent psychiatric inpatients who report histories of childhood abuse. Am J Psychiatry 156: 538-543. [Crossref]

6. Lieb K, Zanarini MC, Schmahl C, Linehan MM, Bohus M (2004) Borderline personality disorder. Lancet 364: 453-461. [Crossref]

7. Ludaescher P, Greffrath W, Schmal C, Kleindienst N, Kraus A, et al. (2009) A cross-sectional investigation of discontinuation of self-injury and normalizing pain perception in patients with borderline personality disorder. Acta Psychiatr Scand 120: 62-70. [Crossref]
8. Von Korff M, Alonso J, Ormel J, Angermeyer M, Bruffaerts R, et al. (2009) Childhood psychosocial stressors and adult onset arthritis: Broad spectrum risk factors and allostatic load. Pain 143: 76-83. [Crossref]

9. Imbierowicz K1, Egle UT (2003) Childhood adversities in patients with fibromyalgia and somatoform pain disorder. Eur J Pain 7: 113-119. [Crossref]

10. Postma R, Bicanic I, van der Vaart H, Laan E (2013) Pelvic floor muscle problems mediate sexual problems in young adult rape victims. J Sexual Med 10: 1978-1987. [Crossref]

11. Golding JM1 (1999) Sexual assault history and headache: five general population studies. J Nerv Ment Dis 187: 624-629. [Crossref]

12. Tietjen GE, Brandes JL, Peterlin BL, Eloff A, Dafer RM, et al. (2010) Childhood maltreatment and migraine (Part I). Prevalence and adult revictimization: A multicenter headache clinic survey. Headache 50: 20-31. [Crossref]

13. Campell LC, Riley III JL, Kashikar-Zuck S, Grenillion H, Robinson ME (2000) Somatic, affective and pain characteristics of chronic TMD patients with sexual versus physical abuse histories. J Orofac Pain 14: 112-119. [Crossref]

14. Hauser W, Glaesmer H, Schmutzer G, Brahler E (2012) Widespread pain in older Germans is associated with posttraumatic stress disorder and lifetime employment status - Results of a cross-sectional survey with a representative population sample. Pain 153: 2466-2472. [Crossref]

15. Harlow BL, Stewart EG (2005) Adult-onset vulvodynia in relation to childhood violence victimization. Am J Epidemiol 161: 871-880. [Crossref]

16. Walker EA, Gelfand AN, Gelfand MD, Katon WJ (1995) Psychiatric diagnoses, sexual and physical victimization, and disability in patients with irritable bowel syndrome or inflammatory bowel disease. Psychol Med 25:1259-1267. [Crossref]

17. Pietrek C, Elbert T, Weierstall R, Müller O, Rockstroh B (2013) Childhood adversities in relation to psychiatric disorders. Psychiatry Res 206: 103-110. [Crossref]

18. Paras ML, Murad MH, Chen LP, Goranson EN, Sattler AL, et al. (2009) Sexual abuse and lifetime diagnosis of somatic disorders: a systematic review and meta-analysis JAMA 302: 550-561. [Crossref]

19. Scarpa A, Haden SC, Abercromby JM (2010) Pathways linking child physical abuse, depression and aggressiveness across genders. J Agg Maltr Trauma 19: 757-776.

20. Spinhoven P, Elzinga BM, Hovens JGFM, et al. (2010) The specificity of childhood adversities and negative life events across the life span to anxiety and depressive disorders. J Aff Disord 126: 103-112. [Crossref]

21. Ackerman PT, Newton JEO, McPherson WB, Jones JG, Dykman RA (1998) Prevalence of posttraumatic stress disorder and other psychiatric diagnoses in three groups of abused children (sexual, physical, and both). Child Abuse Neg 22: 759-774. [Crossref]

22. Chivers-Wilson KA (2006) Sexual assault and posttraumatic stress disorder: A review of the biological, psychological and sociological factors and treatments. McGill J Med 9: 111-118. [Crossref]

23. Ringel Y, Drossman DA, Leserman JL, Suyenobu BY, Wilber K, et al. (2008) Effect of abuse history on pain reports and brain responses to aversive visceral stimulation: An fMRI study. Gastroenterology 134: 396-404. [Crossref]

24. Thomaes K, Dorrepaal E, Draijer N, de Ruiter MB, van Balkom AJ, et al. (2010) Reduced anterior cingulate and orbitofrontal volumes in child abuse-related complex PTSD. J Clin Psychiatry 71: 1636-1644. [Crossref]

25. van Harmelen AL, van Tol MJ, van der Wee NJ, Veltman DJ, Aleman A, et al. (2010) Reduced medial prefrontal cortex volume in adults reporting childhood emotional maltreatment. Biol Psychiatry 68:832-838. [Crossref]

26. Vogt BA, Vogt LJ, Sikes RW (2017) A nociceptive-stress model of adolescent physical abuse induces contextual fear and cingulate nociceptive neuroplasticities. Brain Struct Funct. [Crossref]

27. Terr LC (1991) Childhood traumas: an outline and overview. Am J Psychiatry 148 10-20. [Crossref]

Copyright: (C2017 Vogt BA. This is an open-access article distributed under the terms of the Creative Commons Attribution License, which permits unrestricted use, distribution, and reproduction in any medium, provided the original author and source are credited. 